\title{
A preliminary study on infrared thermal imaging of cross-country skiers and swimmers subjected to endurance exercise
}

\author{
Zofia Drzazga' ${ }^{1}$ (D) Mariusz Binek ${ }^{1} \cdot$ Ilona Pokora $^{2} \cdot$ Ewa Sadowska-Krępa $^{3}$
}

Received: 11 January 2018/Accepted: 16 April 2018/ Published online: 7 May 2018

(C) The Author(s) 2018

\begin{abstract}
This study was focused on the thermal mapping of skin over the selected muscle zones in two groups of elite athletes fully engaged in completely other sports performing about an hour running effort at individual AT intensity. Two groups of elite male athletes, a group of cross-country skiers $(\mathrm{CS} ; N=6)$ and a group of elite endurance swimmers (SW; $N=4)$, were investigated. Thermal images of sportsmen' body at front and from the rear were recorded before and about 1-2 min after exercise test using camera Flir Systems E60. Functional (heart rate, oxygen uptake, workload) as well as biochemical markers (activities of creatine kinase and lactate dehydrogenase, concentration of lactate and haemoglobin) were also assessed. The marked differentiation in skin temperature distribution in cross-country skiers and endurance swimmers subjected to the same endurance exercise on treadmill was observed. There was significant decrease in temperature in upper body temperature in CS group, while SW group revealed a significant increase in temperature of the lower limbs. The calculated total body skin temperature was also influenced by practicing training of elite athletes. Some significant correlations of physiological, biochemical and morphological parameters (\% fat) with average temperature after exercise test were found for different muscle zones in swimmers and cross-country skiers. Statistical analysis showed that workload had the most impact on skin temperature changes, especially in swimmers. The results provide additional information on the muscle work in the different sport disciplines and may be helpful in efficiency evaluation of elite athletes.
\end{abstract}

Keywords IR thermal mapping · Training · Cross-country skiers · Swimmers · Muscles · Biochemical markers · Functional factors

Zofia Drzazga

zofia.drzazga@us.edu.pl

1 Department of Medical Physics, A. Chełkowski Institute of Physics, The Silesian Centre for Education and Interdisciplinary Research, University of Silesia in Katowice, ul. 75 Pułku Piechoty 1A, 41-500 Chorzow, Poland

2 Department of Physiological and Medical Sciences, Department of Physiology, The Jerzy Kukuczka Academy of Physical Education in Katowice, ul. Mikołowska 72a, 40-065 Katowice, Poland

3 Department of Physiological and Medical Sciences, Department of Biochemistry, The Jerzy Kukuczka Academy of Physical Education in Katowice, ul. Mikołowska 72a, 40-065 Katowice, Poland

\section{Introduction}

Infrared thermography is a non-invasive and easy-to-perform method of imaging, and it is becoming useful in different modalities of clinical medicine including sports medicine [1-4]. The aim of medical infrared thermography (MIT) use in sports medicine is not to be a substitute for clinical examination, but to enhance and support it. It can be concluded that MIT is a reliable, low-cost detection tool that should be applied for pre-scanning athletes. Athletes are exposed to many physical stresses during training and competition season. Overuse reactions and so-called minor traumas are very frequent; therefore, early detection is critical to avoid injuries. Research suggests that the most beneficial application of MIT is the screening of individuals for overuse injuries [3]. Moreover, thermal imaging can give important information about state of sportsman health and recovery after different exercises. What is more, 
examined changes of temperature during training, can get impact of physical stress to temperature during this training. The skin thermal response depends on a number of specific physiological adjustments as body fluid homeostasis, cardiovascular fitness, muscle metabolism and athlete's health, which allow to establishing interesting applications in sport. In professional sport, many details as possible about athlete are needed. Using thermography can give as some more knowledge about muscle preservation $[3,4]$.

Endurance competitive sport such as skiing or swimming imposes substantial energy, mechanical, mental and emotional burdens on the human. This reflects, among other things, on a number of biochemical and haematological properties, which display significant differences between athletes and non-athletes in blood samples collected at rest and after exercise. Most prominent among these properties are lactate (LA) concentration and activities of creatine kinase (CK) and lactate dehydrogenase (LDH) $[5,6]$. The post-exercise blood LA level is very useful indicator of both the extent of involvement of anaerobic processes during work and anaerobic work capacity in subjects. In turn, increase in plasma activities of $\mathrm{CK}$ and LDH due to their leakage from cell into the extracellular fluids is generally considered as being indicative of cellular damage. Therefore, a daily monitoring of training status takes place with measurement of these parameters in plasma [7-13].

Cross-country skiing is the most demanding sport aimed at endurance which requires one the highest peak oxygen uptake. However, to reach a world-class level in competitions skiers have increased other physiological factors affecting top speed on skis, such as muscular strength and the ability to generate high power $[14,15]$. Anaerobic threshold related to oxidative capacity of muscle in young female cross-country skiers was discussed [13]. What's more biomechanical aspects of complex movement (double poling) were studied by EMG [16]. However, according to our knowledge correlations between thermal parameters and biochemical factors in athletes have not been analysed yet except for the lactate level. Lactate threshold against temperature during maximal aerobic test in athletes [11] and in capillary blood during post-exercise recovery in non-trained subjects [12] was reported.

On the other hand, thermography studies for swimmers were performed more often [17-20]. Purpose of quantifying the influence of the swimming style on the cartographies of cutaneous temperatures of a swimmer by infrared thermography was presented [17]. Temperature changes in particular skin areas in the course of front crawl swimming were evaluated [18]. An assessment of energetic-metabolic activity of selected muscles of upper extremities and body during breaststroke swimming through infrared thermography was described taking into account sides of body [19]. Changes in infrared radiation and overloaded structures of the musculoskeletal system in swimmers were also detected [20]. However, we do not find any article comparing evaluation of skin temperature of athletes practicing endurance swimming and cross-country skiing taking into consideration physiological and biochemical factors also.

The aim of this study was to assess the skin temperature distribution in two groups of elite athletes: cross-country skiers and swimmers fully engaged in completely other sports as a response to the same exercise test (running on treadmill) as well as to analyse the impact of physiological and biochemical factors on skin temperature changes over the selected muscles. We would like using thermography to obtain temperature patterns characteristic for the elite sportsmen which could provide an information on body's adaptation to physical effort, efficiency of thermoregulatory system, enabling athletes to continue performing as their highest sport level.

\section{Materials and methods}

\section{Subjects}

Two groups of elite male athletes, a group of cross-country skiers (CS; $N=6)$ and a group of elite endurance swimmers (SW; $N=4$ ) from Academic Sports Association (AZS) in the Jerzy Kukuczka Academy of Physical Education, volunteered to participate in this study. The crosscountry skiers are the members of Polish National Team, and the swimmers are taking part in the world championships. The main limitation of our study is the small number of participants recruited from the elite athletes, especially swimmers.

All subjects were in the preparatory period of the annual training plan. They were informed of the purpose, possible risks and the benefits of the study before giving their written consent to participate. The study protocol conformed to the ethical guidelines of the World Medical Association Declaration of Helsinki and was approved by the Ethics Committee of the Jerzy Kukuczka Academy of Physical Education in Katowice, Poland.

At the beginning of study, the subjects' body mass and composition and aerobic fitness were assessed. The basic characteristics of athletes are presented in Table 1.

\section{Procedure}

In order to determine the aerobic fitness, the maximal oxygen uptake $\left(\mathrm{VO}_{2 \max }\right)$ and lactate threshold (AT) were determined directly, during $\mathrm{VO}_{2 \max }$ test. The $\mathrm{VO}_{2 \max }$ test 
Table 1 Athletes'

characteristics

\begin{tabular}{|c|c|c|}
\hline Parameters & Cross-country skiers, $N=6$ & Swimmers, $N=4$ \\
\hline Age/years & $23 \pm 2.68$ & $21.5 \pm 2.08$ \\
\hline $\mathrm{BH} / \mathrm{cm}$ & $179.07 \pm 3.0$ & $185.25 \pm 4.57$ \\
\hline $\mathrm{BW} / \mathrm{kg}$ & $73.47 \pm 3.16$ & $80.75 \pm 6.73$ \\
\hline $\mathrm{BF} / \mathrm{kg}$ & $5.3 \pm 1.21$ & $7.52 \pm 5.56$ \\
\hline $\mathrm{VO}_{2 \max } / \mathrm{L} \min ^{-1}$ & $4.68 \pm 0.55$ & $4.78 \pm 0.31$ \\
\hline $\mathrm{VO}_{2 \max } / \mathrm{mL} \mathrm{kg}^{-1} \min ^{-1}$ & $64 \pm 5.85$ & $58 \pm 8.48$ \\
\hline BMI & $22.93 \pm 1,03$ & $23.55 \pm 2.08$ \\
\hline$\%$ fat & $7.23 \pm 1.70$ & $9.32 \pm 663$ \\
\hline
\end{tabular}

Data are presented as mean $\pm \mathrm{SD}$

$\mathrm{BH}$, body height; $\mathrm{BW}$, body mass; $\mathrm{BF}$, total body fat; $\mathrm{VO}_{2 \max }$, maximal oxygen uptake; $\mathrm{BMI}$, body mass index

involved an incremental treadmill running to exhaustion: starting at $6 \mathrm{~km} \mathrm{~h}^{-1}, 0 \%$ gradient with speed increasing by $2 \mathrm{~km} \mathrm{~h}^{-1}$ every $3 \mathrm{~min}$, until speed of $14 \mathrm{~km} \mathrm{~h}^{-1}$. Thereafter, the treadmill gradient has been increased by $2.5 \%$ every 3 min until volitional exhaustion. During the exercise test, heart rate (HR) (Polarelectro, Finland) and oxygen uptake $\left(\mathrm{VO}_{2}\right)$ (was applied-open circuit spirometer, OXYCON, Jaeger, Germany) were measured and blood lactate concentration was determined. Lactate threshold (AT) was designated as the point (workload) at which blood lactate increased exponentially.

Two weeks after preliminary testing, all participants were tested again on a treadmill. A proper exercise test involved about an hour of running effort at individual AT intensity. Thermal images of sportsmen' body at front and from the rear (nine thermal images for each subject including head) were recorded using camera Flir Systems E60 with resolution of camera $320 \times 240$ pixels and with sensitivity $0.05 \mathrm{~K}$ before and about 1-2 min after the completion of exercise test (after exercise used consistently thereafter). All measurements were performed in a similar way to the Glamorgan Protocol including thermal imaging in its medical standards [21, 22]. The results were analysed by using a ThermaCAM TM Researcher Pro 2.8 SR-3 focusing on the muscle zones according the model proposed by Fernández-Cuevas et al. [2].

Blood samples were drawn from the antecubital vein into test tubes anticoagulated with heparin at rest $(0)$ and immediately following the run (T). Fresh plasma samples were assayed for activities of creatine kinase (CK, EC 2.7.3.2) and lactate dehydrogenase (LDH, EC 1.1.1.27), and concentration of lactate (LA), using diagnostic kits from Randox Laboratories (CK522, LD3818 and LC2389, respectively). Haemoglobin $(\mathrm{Hb})$ was assayed by a standard cyan-methaemoglobin method using a diagnostic kit (HG980, Randox, UK).

All experiments were performed in a human functional testing laboratory, Katowice Academy of Physical
Education on treadmill $\mathrm{H} / \mathrm{P} / \mathrm{Cosmos}$ Pulsar at $19 \pm 0.5{ }^{\circ} \mathrm{C}$ ambient temperature, $56 \pm 3 \%$ relative humidity and $985 \pm 5 \mathrm{hPa}$ atmospheric pressure.

\section{Statistical analysis}

The results were analysed in Statistica 12. Variables' values were compared using a Wilcoxon and paired Student $t$ test. Statistical significance was accepted at $p<0.05$. Correlation coefficients between two variables were calculated using a Pearson-product moment correlation matrix.

\section{Results and discussion}

This study used a running exercise model performed at individual anaerobic threshold to evaluate the contribution of physiological factors and biochemical markers in determining the changes in skin temperatures after exercise in cross-country skiers and endurance swimmers.

\section{Thermography assessment}

Representative thermographs of body surface including upper and lower part, before and after running exercise for ski-runners and swimmers, are shown in Figs. 1 and 2, respectively. ROIs of interest including 22 muscle zones for each sportsman were taken into account. Thermographic recordings present a complex physiological response of the skin to similar exercise load at individual AT intensity of cross-country skiers and endurance swimmers. It should be noted that skin temperature changes of body surface due to exercise test were different in crosscountry skiers and endurance swimmers. A marked drop of the temperature in upper part of body immediately after physical exertion in cross-country skiers unlike swimmers was observed. What is more, after exercise the upper part 
(a)
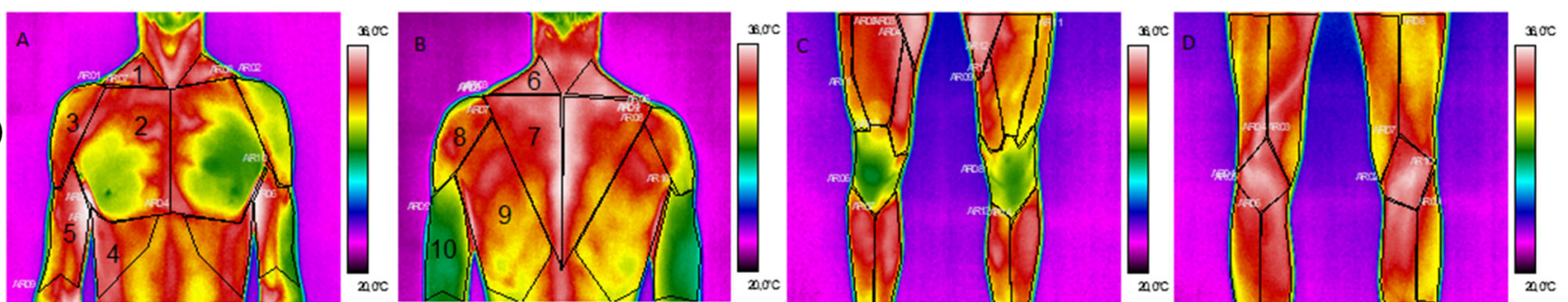

(b)
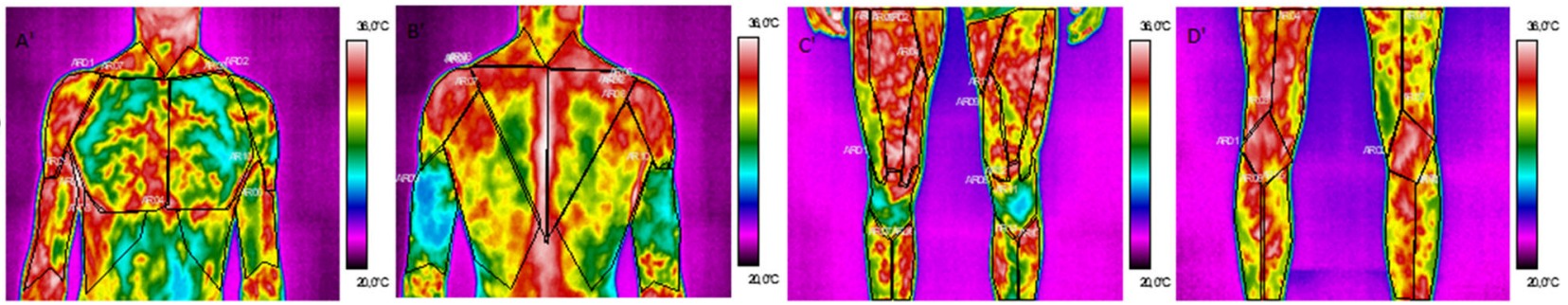

Fig. 1 Example thermograms of body surface for cross-country skiers in front $\mathrm{A}, \mathrm{A}^{\prime}, \mathrm{C}, \mathrm{C}^{\prime}$ and $\mathrm{B}, \mathrm{B}^{\prime}, \mathrm{D}, \mathrm{D}^{\prime}$ from back surface of body registered $\mathbf{a}$ before exercise, $\mathbf{b}$ after exercise test. 1 trapezios muscle,

2 pectoralis major, 3 deltoid muscle, 4 serratus anterior, 5 biceps brachii, 6 trapezios muscle (neck), 7 trapezius muscle (back), 8 rear of deltoid muscle, 9 latissimus dorsi, 10 triceps brachii

(a)

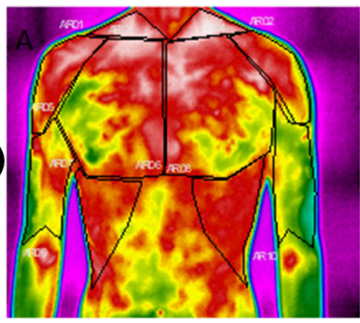

(b)
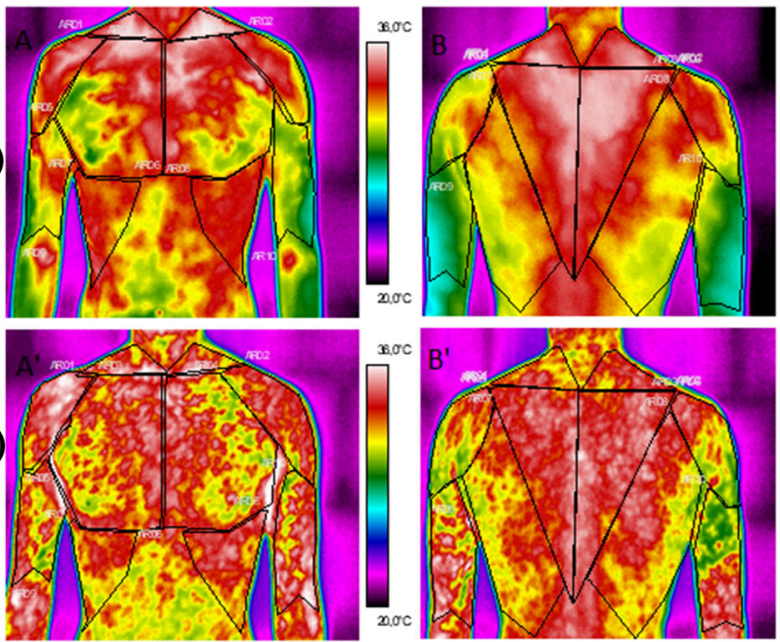

Fig. 2 Example thermograms of body surface for swimmers in front $\mathrm{A}, \mathrm{A}^{\prime}, \mathrm{C}, \mathrm{C}^{\prime}$ and $\mathrm{B}, \mathrm{B}^{\prime}, \mathrm{D}, \mathrm{D}^{\prime}$ from back surface of body registered a before exercise, $\mathbf{b}$ after exercise test. 1 vastus lateralis, 2 rectus femoris, 3 muscles of pubic bone, 4 vastus medialis, 5 knee (at front),

of body in cross-country skiers was cooler than legs, while in swimmers skin temperature of the lower part of body was hotter than temperature of the upper part of body. Tanda [23] has evaluated the response of skin temperature to different types of running exercise on treadmill under controlled laboratory conditions. The author indicated a fall in total body skin temperature during the initial stage of running exercise, regardless of the type of work (with graded or constant load). In the case of constant load exercise, the skin temperature decreases at the beginning of the work, followed by a little increase over time. It is argued that the initial decline and the subsequent slight rise in skin temperature is the net result of the competition between the vasoconstrictor response, which lasts as long

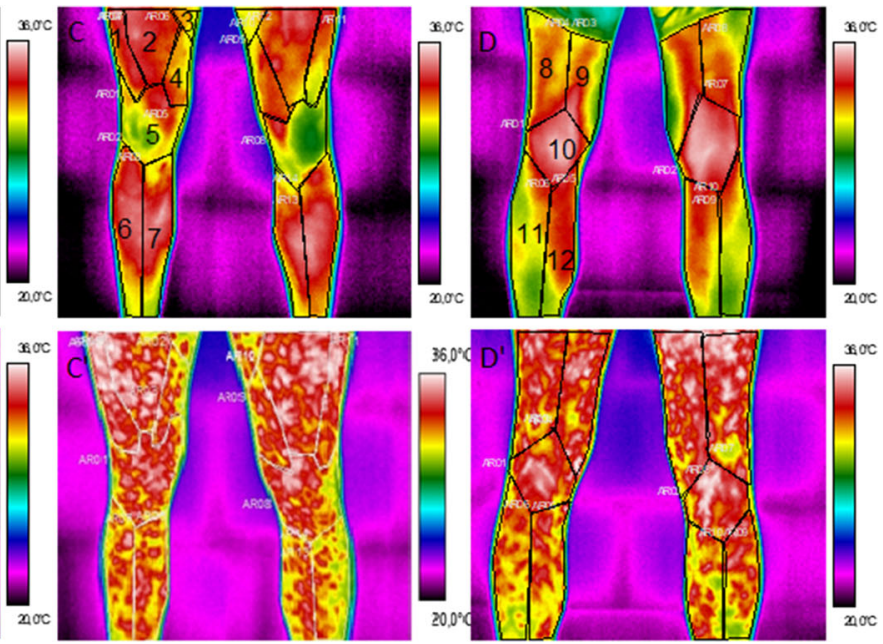

6 tibialis anterior, 7 soleus, 8 biceps femoris, 9 remaining thin muscles, 10 knee (rear), 11 gastrocnemius caput laterale, 12 gastrocnemius caput mediale

as the exercise is continued, and the vasodilatory response initiated after cessation of exercise, induced by the increasing body temperature.

In this study, thermographic data indicated that skin response to exercise test was specific for the group of tested subjects. There was probably a difference in the blood distribution and sweat gland recruitment pattern or sweat output per gland during exercise in cross-country skiers and swimmers. In nearly all areas, left-right difference of temperature is not significant similar as in [19].

In order to get better insight into problem, differences in skin temperature measured before and after exercise test $\Delta T_{\text {sk }}\left(\Delta T_{\text {sk }}=T_{\text {skin after }}-T_{\text {skin before }}\right)$ for the selected muscle zones were calculated. Mean $\Delta T_{\mathrm{sk}}$ over the muscles 
Table 2 Mean $\Delta T_{\text {sk }} \pm \mathrm{SD}$ values of upper body muscle zones for elite swimmers and elite cross-country skiers as a response to running exercise
Table 3 Mean $\Delta T_{\mathrm{sk}} \pm \mathrm{SD}$ values of lower body muscle zones for elite swimmers and elite cross-country skiers as a response to running exercise

\begin{tabular}{|c|c|c|c|c|}
\hline \multirow[t]{2}{*}{ Muscle } & \multicolumn{2}{|c|}{ Swimmers, $N=4$} & \multicolumn{2}{|c|}{ Cross-country skiers, $N=6$} \\
\hline & $\Delta T_{\mathrm{sk}} \pm \mathrm{SD} /{ }^{\circ} \mathrm{C}$ & $p$ & $\Delta T_{\mathrm{sk}} \pm \mathrm{SD} /{ }^{\circ} \mathrm{C}$ & $p$ \\
\hline Forehead & $0.58 \pm 0.4$ & 0.17 & $0.50 \pm 1.5$ & 0.32 \\
\hline Cheeks & $\mathbf{3 . 5} \pm 0.8$ & 0.0004 & $\mathbf{2 . 8 9} \pm 1.4$ & $\mathbf{0 . 0 0 0 0}$ \\
\hline Trapezius muscle & $-0.43 \pm 0.4$ & 0.25 & $-\mathbf{1 . 4 8} \pm 0.9$ & 0.0001 \\
\hline Deltoid muscle & $0.03 \pm 0.6$ & 0.90 & $-\mathbf{1 . 4 6} \pm 1.4$ & 0.004 \\
\hline Pectoralis major & $0.24 \pm 0.4$ & 0.40 & $-\mathbf{2 . 0 6} \pm 1.3$ & 0.0002 \\
\hline Serratus anterior & $0.26 \pm 0.3$ & 0.50 & $-\mathbf{2 . 0 2} \pm 1.4$ & 0.0001 \\
\hline Abdomen & $0.13 \pm 0.4$ & 0.75 & $-\mathbf{2 . 6 1} \pm 1.3$ & 0.0000 \\
\hline Biceps brachii & $0.56 \pm 0.7$ & 0.50 & $-\mathbf{1 . 2 5} \pm 1.2$ & 0.003 \\
\hline Trapezius mascle (neck) & $-0.08 \pm 0.3$ & 0.26 & $-0.48 \pm 1.3$ & 0.20 \\
\hline Rear of deltoid muscle & $0.50 \pm 0.6$ & 0.25 & $-0.2 \pm 0.8$ & 0.70 \\
\hline Trapezius muscle (back) & $0.68 \pm 0.6$ & 0.15 & $-\mathbf{0 . 6 6} \pm 0.7$ & 0.002 \\
\hline Latissimus dorsi & $0.57 \pm 0.5$ & 0.42 & $-\mathbf{0 . 9 3} \pm 1.0$ & 0.0006 \\
\hline Triceps brachii & $0.79 \pm 1.4$ & 0.30 & $-1.04 \pm 2.2$ & 0.15 \\
\hline
\end{tabular}

Significant results of $\Delta T_{\mathrm{sk}}$ of muscles, according to a paired student $t$ test, are in bold

\begin{tabular}{|c|c|c|c|c|}
\hline \multirow[t]{2}{*}{ Muscle } & \multicolumn{2}{|c|}{ Swimmers, $N=4$} & \multicolumn{2}{|c|}{ Cross-country skiers, $N=6$} \\
\hline & $\Delta T_{\mathrm{sk}} \pm \mathrm{SD} /{ }^{\circ} \mathrm{C}$ & $p$ & $\Delta T_{\mathrm{sk}} \pm \mathrm{SD} /{ }^{\circ} \mathrm{C}$ & $p$ \\
\hline Vastus lateralis & $1.10 \pm 0.7$ & 0.1 & $-0.01 \pm 1.5$ & 0.75 \\
\hline Rectus femoris & $\mathbf{1 . 5 3} \pm 0.9$ & 0.049 & $-0.2 \pm 1.9$ & 0.55 \\
\hline Vastus medialis & $-0.19 \pm 1.2$ & 0.2 & $-0.11 \pm 1.2$ & 0.5 \\
\hline Biceps femoris & $\mathbf{1 . 4 9} \pm 0.7$ & 0.01 & $-0.46 \pm 1.1$ & 0.6 \\
\hline Remaining thigh muscles & $\mathbf{1 . 3 6} \pm 0.8$ & 0.02 & $-0.37 \pm 1.2$ & 0.4 \\
\hline Knees (at front) & $\mathbf{2 . 6 3} \pm 0.7$ & 0.01 & $0.4 \pm 2.3$ & 0.5 \\
\hline Knees (rear) & $0.54 \pm 0.6$ & 0.1 & $-0.47 \pm 1.3$ & 0.1 \\
\hline Tibialis anterior & $0.77 \pm 0.6$ & 0.15 & $-0.02 \pm 1.2$ & 0.6 \\
\hline Soleus & $\mathbf{1 . 4 8} \pm 0.5$ & 0.02 & $0 \pm 1.3$ & 0.3 \\
\hline Gastrocnemius caput laterale & $\mathbf{1 . 2 0} \pm 0.6$ & 0.004 & $-0.23 \pm 0.9$ & 0.6 \\
\hline Gastrocnemius caput mediale & $\mathbf{1 . 0 6} \pm 0.3$ & 0.003 & $-0.17 \pm 0.9$ & 0.7 \\
\hline
\end{tabular}

Significant results of $\Delta T_{\mathrm{sk}}$ of muscles, according to a paired student $t$ test, are in bold in upper part of body and lower limbs for both groups is listed in Tables 2 and 3, respectively.

It should be noted that temperature changes over specified muscle zones were relatively big and showed significant temperature increase in the lower limbs in SW in the range $1.06-2.63{ }^{\circ} \mathrm{C}$ and temperature drop in the upper part of body for $\mathrm{CS}$ in the range from -0.66 to $-2.02{ }^{\circ} \mathrm{C}$. However, $\Delta T_{\text {sk }}$ of head (cheeks and forehead) due to running exercise was very similar in the both studied groups.

It should be noted that statistically significant drop of the temperature occurs only for upper part of body in the cross-country skiers and increase in the temperature for the lower limbs in the swimmers. These results indicate that practicing sports may affect the thermal map of skin over the muscles. Tanda [24], Merla et al. [25] and Ludwig et al. [26] documented the different temperature responses of thighs, forearms and trunk as well as the presence of hyperthermal spots over the entire body during the recovery; these findings are likely to be related to the cutaneous blood flow adaptation to the specific exercise and probably participants' thermal activity profile-related to type of training adaptation. A type of sport can induce specific to the nature of the training activity physiological and morphological adaptations. Following training, the cardiovascular and thermoregulatory systems along with their components go through various adaptive changes. The nature of these systemic and organ adaptations is highly specific to a particular sport with respect to the type of conditioning and apparent stimuli to which the athlete is subjected [27]. The shape of the time distribution of skin temperature was different for the swimmers and crosscountry runners participating in the constant AT load 
exercise, but the start and the extent of the temperature rise during the recovery seem to be related to the individual grade of vasoregulation or body structure (affecting the core to skin thermal conductance), as documented in the Tanda's research $[23,24]$. It is argued that this diversity of the individual response to running exercise may reflect a different level of physical fitness (e.g. aerobic capacity $\mathrm{VO}_{2 \max }$ ) and participants' physical activity profile (specificity of running exercise test for cross-country skiers but not for swimmers) was associated with a development of different types of training adaptations in elite cross-country skiers and swimmers. It was indicated that swimmers have very specific training adaptations even compared with triathletes [28].

The drop of skin temperature over the selected muscle zones of the upper part of body in CS subjects seems to be associated with cooling effect of sweat evaporation. Sweating is the most important thermoregulatory reaction by which heat balance is maintained following a rise in body temperature during exercise-induced heat load. Evaporation of sweat from the skin surface has a cooling effect because evaporation is an endothermic process. Moreover, there are more sweat glands in upper than lower part of body since the marked temperature drop because of exercise observed in cross-country skiers seems to be accepted. On the other hand, occurrence of a big amount of sweat can lead to disturbances in the real temperature associated with the change in muscle metabolism by exercise and consequently it may slightly distort the interpretation of the temperature distribution on the body surface. Decrease in skin temperature immediately after exercise (45-min endurance exercise; at $60 \% \mathrm{VO}_{2 \max }$ ) [2] and during a graded exercise test [29] was reported. Marked drop of the skin temperature due to endurance training in normobaric hypoxia was also observed [30]. However, for swimmers training in water the sweating is not the main way to lose the heat since swimmers may have a little different adapted metabolism to such effort as running exercise what was observed during running exercise.

In order to increase the readability of skin temperature changes, whole body mean skin temperature was calculated. There are several possibilities to estimate whole body temperature $[23,31,32]$. In this paper, we decided to evaluate whole body temperature before and 1-2 min after exercise using two methods, the first according to model used in paper by Cholewka et al. [32] and the second based on the model proposed by Choi [31] and partly modified by Tanda [23].

In the first approximation, the mean temperature of whole body was evaluated using formula (1)

$$
\begin{aligned}
T_{\text {sk }}= & 0.32 T_{\text {tibia }}+0.17 T_{\text {back }}+0.18 T_{\text {chest }}+0.14 T_{\text {arm }} \\
& +0.07 T_{\text {head }}+0.06 T_{\text {thigh }}+0.06 T_{\text {abdomen }}
\end{aligned}
$$

which is presented in Table 4 for the both elite skiers and swimmers.

In the next method, mean temperatures of all muscle zones possible to analyse from our thermographic images were taken into account ( $n=27)$. Unfortunately, we could not extract contribution of foot and hand skin temperature from our infrared measurements. However, one can see (Table 4) that results obtained from formula (2)

$T_{\mathrm{sk}}=\left(\sum_{n} T_{\text {mean muscle zone }}\right) / n$

are very close to those obtained from formula (1).

The calculated total body skin temperatures after running exercise on treadmill show relatively small $\left(0.6-0.8^{\circ} \mathrm{C}\right)$ changes similarly as in studies reported in [23]. However, in our investigation whole body temperature depends on practicing training of elite athletes. It should be noted that $T_{\mathrm{sk}}$ indicates the same tendencies as the most muscle zones in upper part of body for CS and in lower part of body for SW, respectively. An evolution of total body skin temperature during running exercise on treadmill is compatible with regional temperature response taking into account only the before and after exercise skin temperature values. However, temporally monitoring the topography of whole body temperature as well as selected body surface temperatures seems to be important in the development of physiological models and heat flux analyses [23, 33].

\section{Physiological and biochemical measurements}

Physiological parameters as well as biochemical parameters are collected in Table 5.

AT intensity exercise was performed longer with a greater power (WR and WR/kg) in the CS than $\mathrm{SW}$ group, whereas terminal lactate concentration achieved in this group was lower in comparison with the SW group (Table 5). However, in both groups an increase in CK activity was the same. These results may indicate that cross-country skiers have a better aerobic capacity than the SW group which allowed them to continue this effort with a smaller share of anaerobic metabolism.

Interesting are also observations on changes in plasma $\mathrm{CK}$ and LDH activities. Although there was a large variability in $\mathrm{CK}$ response among the all subjects, the time course of changes in the activities of this enzyme was similar in each group. The pretest LDH activities were comparable in both groups of subjects, whereas test performed by the swimmers resulted in a higher increment in LDH activity (21\% increase) than in the cross-country skiers (18\% increase). Post-exercise changes in LDH activity showed that plasma activity of this enzyme 
Table 4 Mean cutaneous whole body temperature $T_{\mathrm{sk}} \pm \mathrm{SD}$ values for swimmers and crosscountry skiers before and after running exercise

\begin{tabular}{|c|c|c|c|c|c|c|}
\hline \multirow[t]{3}{*}{ Method } & \multicolumn{3}{|c|}{ Swimmers, $N=4$} & \multicolumn{3}{|c|}{ Cross-country skiers, $N=6$} \\
\hline & \multicolumn{3}{|l|}{$T_{\mathrm{sk}} \pm \mathrm{SD} /{ }^{\circ} \mathrm{C}$} & \multicolumn{3}{|l|}{$T_{\mathrm{sk}} \pm \mathrm{SD} /{ }^{\circ} \mathrm{C}$} \\
\hline & Before training & After training & $p$ & Before training & After training & $p$ \\
\hline (1) & $32.50 \pm 0.45$ & $33.23 \pm 0.61$ & 0.009 & $32.40 \pm 0.70$ & $31.73 \pm 1.03$ & 0.10 \\
\hline (2) & $32.51 \pm 0.37$ & $33.30 \pm 0.63$ & 0.009 & $32.39 \pm 0.69$ & $31.85 \pm 1.06$ & 0.10 \\
\hline
\end{tabular}

Significant differences of $T_{\text {sk }}$ before and after treadmill exercise, according to a paired student $t$ test, are shown in bold

\begin{tabular}{|c|c|c|}
\hline Variable & Cross-country skiers, $N=6$ & Swimmers, $N=4$ \\
\hline $\mathrm{HR}_{\mathrm{T}} /$ beats $\min ^{-1}$ & $182 \pm 6.7$ & $180.5 \pm 8.2$ \\
\hline $\mathrm{WR}_{\mathrm{T}} / \mathrm{W}$ & $295.6 \pm 20.1$ & $275.8 \pm 2.9$ \\
\hline $\mathrm{WR} / \mathrm{kg} \mathrm{W}^{-1} \mathrm{~kg}^{-1}$ & $4.0 \pm 0.08$ & $3.43 \pm 0.46$ \\
\hline$V_{\mathrm{T}} / \mathrm{km} \mathrm{h}^{-1}$ & 14.0 & 12.0 \\
\hline Total time of exercise/min & $55.0 \pm 10.5$ & $35.0 \pm 16.9$ \\
\hline $\mathrm{LA}_{0} / \mathrm{mM}$ & $1,2 \pm 0.3$ & $1.7 \pm 0.6$ \\
\hline $\mathrm{LA}_{\mathrm{T}} / \mathrm{mM}$ & $3.8 \pm 0.8$ & $5.13 \pm 3.5$ \\
\hline$\Delta \mathrm{LA} / \mathrm{mM}$ & $2.6 \pm 0.8$ & $3.41 \pm 3.01$ \\
\hline $\mathrm{CK}_{0} / \mathrm{U} \mathrm{L}^{-1}$ & $213.2 \pm 13.5$ & $79.6 \pm 8$ \\
\hline $\mathrm{CK}_{\mathrm{T}} / \mathrm{U} \mathrm{L}^{-1}$ & $283.9 \pm 145$ & $148.4 \pm 50$ \\
\hline$\Delta \mathrm{CK} / \mathrm{U} \mathrm{L}^{-1}$ & $70.7 \pm 70.19$ & $68.8 \pm 46$ \\
\hline $\mathrm{Hb}_{0} / \mathrm{g} \mathrm{dL}^{-1}$ & $15.9 \pm 0.43$ & $15.4 \pm 0.3$ \\
\hline $\mathrm{Hb}_{\mathrm{T}} / \mathrm{g} \mathrm{dL}^{-1}$ & $16.3 \pm 0.51$ & $16.4 \pm 0.6$ \\
\hline$\Delta \mathrm{Hb} / \mathrm{g} \mathrm{dL}^{-1}$ & $0.45 \pm 0.41$ & $1.0 \pm 0.6$ \\
\hline $\mathrm{LDH}_{\mathrm{o}} / \mathrm{U} \mathrm{L}^{-1}$ & $323.3 \pm 84$ & $232.1 \pm 47$ \\
\hline $\mathrm{LDH}_{\mathrm{T}} / \mathrm{U} \mathrm{L}^{-1}$ & $382.6 \pm 77.6$ & $254.3 \pm 56.2$ \\
\hline$\Delta \mathrm{LDH} / \mathrm{U} \mathrm{L}^{-1}$ & $59.4 \pm 24.5$ & $22.26 \pm 15$ \\
\hline
\end{tabular}

$\mathrm{HR}_{\mathrm{T}}$, terminal heart rate; $\mathrm{WR}_{\mathrm{T}}$, terminal work load; $\mathrm{WR} / \mathrm{kg}$, terminal work load, per $\mathrm{kg} \mathrm{BM} ; V_{\mathrm{AT}}$, velocity at AT during treadmill running; $\mathrm{LA}_{0}$, lactate concentration at the beginning of exercise; $\mathrm{LA}_{\mathrm{T}}$ terminal lactate concentration; $\triangle \mathrm{LA}$, increase in lactate concentration during exercise test; $\mathrm{CK}_{0}$, creatine kinase activity before exercise test; $\mathrm{CK}_{\mathrm{T}}$, creatine kinase activity achieved immediately after exercise test; $\Delta \mathrm{CK}$, increase in creatine kinase activity during exercise; $\mathrm{Hb}_{0}, \mathrm{Hb}_{\mathrm{T}}$, basal and terminal of the blood haemoglobin concentration, respectively; $\Delta \mathrm{Hb}$, increase in the blood haemoglobin concentration during exercise test; $\mathrm{LDH}_{0}$, lactate dehydrogenase activity at the beginning of exercise; $\mathrm{LDH}_{\mathrm{T}}$, lactate dehydrogenase activity achieved immediately after exercise test; $\Delta \mathrm{LDH}$, increase in lactate dehydrogenate activity during exercise response to exercise depended on the training status. Differences in post-exercise $\mathrm{CK}$ and $\mathrm{LDH}$ levels in plasma may reflect dissimilarities in the rates of penetration through the sarcolemma and different degrees of injury in distinct fibre types. Moreover, ski-runners exhibited less acidification $(\triangle \mathrm{LA})$ despite the increased load (WR and $\mathrm{WR} / \mathrm{kg}$ ) and longer exercise.

\section{Correlations between temperature and physiological/biochemical markers}

Analysis of relationships of skin temperature with physiological and biochemical factors was focused on zones of the muscles that worked the most intensively while running exercise was performed; there were vastus lateralis, biceps femoris, gastrocnemius, soleus in the lower part of body and biceps brachii and pectoralis major in the upper part of body, mainly [34, 35]. The calculated correlations between temperature and physiological as well as biochemical factors are presented in Table 6.

In general, a small number of correlations are found statistically significant that may be due to the small size of the groups studied. Nevertheless, it follows from Table 5 that temperature correlations with functional parameters such as $\mathrm{WR}_{\mathrm{T}}$ and $\mathrm{VO}_{2 \max }$ can be strong and statistical significant $(p<0.05)$ or show marked tendency $(p \leq 0.1)$ for some muscles of legs working intensively during experimental exercise performed on treadmill in 
Table 6 Correlations $(r)$ of physiological and biochemical parameters $\left(\mathrm{VO}_{2 \max }, \mathrm{WR}_{\mathrm{T}}, \mathrm{LA}_{\mathrm{T}}, \mathrm{LDH}_{\mathrm{T}}\right)$ with average temperature after exercise in selected muscle zones (shown for muscle zones when significant correlation at $p \leq 0.05$ occurred for at least one of the studied groups)

\begin{tabular}{|c|c|c|c|c|c|c|c|c|c|}
\hline \multirow[t]{2}{*}{ Muscle } & \multirow[t]{2}{*}{ Group } & \multicolumn{2}{|c|}{$\mathrm{VO}_{2 \max } / \mathrm{L} \min ^{-1}$} & \multicolumn{2}{|l|}{$\mathrm{WR}_{\mathrm{T}} / \mathrm{W}$} & \multicolumn{2}{|c|}{$\mathrm{LA}_{\mathrm{T}} / \mathrm{mM}$} & \multicolumn{2}{|c|}{$\mathrm{LDH}_{\mathrm{T}} / \mathrm{U} \mathrm{L}^{-1}$} \\
\hline & & $r$ & $p$ & $r$ & $p$ & $r$ & $p$ & $r$ & $p$ \\
\hline \multirow[t]{2}{*}{ Rectus femoris } & SW & -0.88 & 0.12 & -0.94 & 0.05 & -0.72 & 0.27 & 0.73 & 0.26 \\
\hline & $\mathrm{CS}$ & 0.15 & 0.77 & 0.21 & 0.68 & 0.21 & 0.68 & -0.04 & 0.93 \\
\hline \multirow[t]{2}{*}{ Knees (at front) } & SW & -0.22 & 0.67 & 0.02 & 0.96 & 0.68 & 0.13 & -0.09 & 0.86 \\
\hline & $\mathrm{CS}$ & -0.85 & 0.14 & -0.94 & 0.05 & -0.76 & 0.23 & 0.76 & 0.23 \\
\hline \multirow[t]{2}{*}{ Soleus } & SW & -0.7 & 0.23 & -0.99 & 0.01 & -0.67 & 0.32 & 0.86 & 0.13 \\
\hline & $\mathrm{CS}$ & -0.37 & 0.46 & -0.45 & 0.36 & 0.87 & 0.02 & 0.06 & 0.90 \\
\hline \multirow[t]{2}{*}{ Biceps femoris } & SW & -0.65 & 0.34 & -0.98 & 0.01 & -0.48 & 0.51 & 0.92 & 0.05 \\
\hline & $\mathrm{CS}$ & 0.45 & 0.36 & 0.36 & 0.47 & 0.09 & 0.85 & 0.25 & 0.62 \\
\hline \multirow[t]{2}{*}{ Remaining thigh muscles } & SW & -0.56 & 0.43 & -0.99 & 0.01 & -0.57 & 0.42 & 0.96 & $\mathbf{0 . 0 3}$ \\
\hline & $\mathrm{CS}$ & 0.21 & 0.68 & 0.17 & 0.73 & 0.38 & 0.45 & 0.25 & 0.63 \\
\hline \multirow[t]{2}{*}{ Gastrocnemius caput mediale } & SW & -0.94 & 0.05 & -0.80 & 0.19 & -0.52 & 0.47 & 0.53 & 0.46 \\
\hline & $\mathrm{CS}$ & 0.11 & 0.83 & 0.25 & 0.63 & -0.18 & 0.73 & -0.09 & 0.85 \\
\hline
\end{tabular}

Significant correlations $(r)$ between physiological and biochemical parameters and average skin temperature after exercise are shown in bold

swimmers, especially. Earlier negative high correlation between power set on bicycle ergometer and average body surface temperature of athletes during progressive test was reported [32]. The strong and statistically significant influence of aerobic fitness $\left(\mathrm{VO}_{2 \max }\right)$ on the change in surface temperature of the upper limbs immediately after the exercise for athletes who professionally played volleyball was also reported [36]. It is known that changes in concentration of biochemical metabolic markers depend on the type, intensity and exercise duration as well as were related to individual subjects' adaptation to exercise and the aerobic fitness level. Previous studies have established these differences based on changes of the thermoregulatory processes depending on the physical level of the subject $[37,38]$. Low-trained subjects release the heat worse than high-trained during exercise and maintain the heat longer time during the recovery process [39]. This is probably due to a higher muscle activation and blood flow in hightrained subjects.

Temperature correlations with biochemical metabolic markers $\left(\mathrm{LA}_{\mathrm{T}}, \mathrm{LDH}_{\mathrm{T}}\right)$ on significance level or tendency occur much less frequently than with physiological factors (Table 6) and are dependent on type of muscle. The studied muscles (especially soleus and gastrocnemius) differ significantly in the contribution of slow twitch (ST) and fast twitch (FT) fibres in the muscle structure which consequently implies differences in the metabolic characteristics of these muscles.

The lack of significant changes in skin temperature over leg muscles (Table 3) and practically negligible temperature correlations between physiological and biochemical markers in cross-country skiers unlike swimmers seems to stem from the fact that CS group is characterised by higher running endurance capacity $\left(\mathrm{VO}_{2 \max }\right)$ than $\mathrm{SW}$ group for which running effort is not as specific as for skiers.

Recently, it has been raised [40] that the temperature distribution at the skin is not directly related to physiological metabolism transforming chemical energy into work and heat. However, infrared radiation can be directly correlated with the temperature distribution of a defined body region [3]. Heat transported by blood is influenced by the gradient between temperature of core tissues and shell temperature represented by surrounding tissues. Peripheral tissues (e.g. fat depot under the skin, subcutaneous fat) may act as insulation layers varying in expansion in dependence of ambient temperature and individual human. A study of surface skin temperature distribution in relation to body composition indicated a lower skin temperature of most body surfaces in obese women [41] than women of normal body mass because the local skin temperatures are influenced by subcutaneous adiposity. Among our studied athletes, higher temperature correlation coefficients with fat content were obtained in the most muscle zones for swimmers unlike ski-runners (Fig. 3).

In human thermoregulatory behaviour, the skin as the thermal input for maintenance of heat balance and temperature regulation during exercise and rest can be considered [42]. Complex of thermal dynamic balance between heat dissipation through the radiation, convection and evaporation of sweat and heat production dependent on its intensity and effort is reflected in thermal imaging of surface skin body. Therefore, thermography is used as a fast, non-invasive method, which can provide indirect information on the body's adaptation to physical effort and 


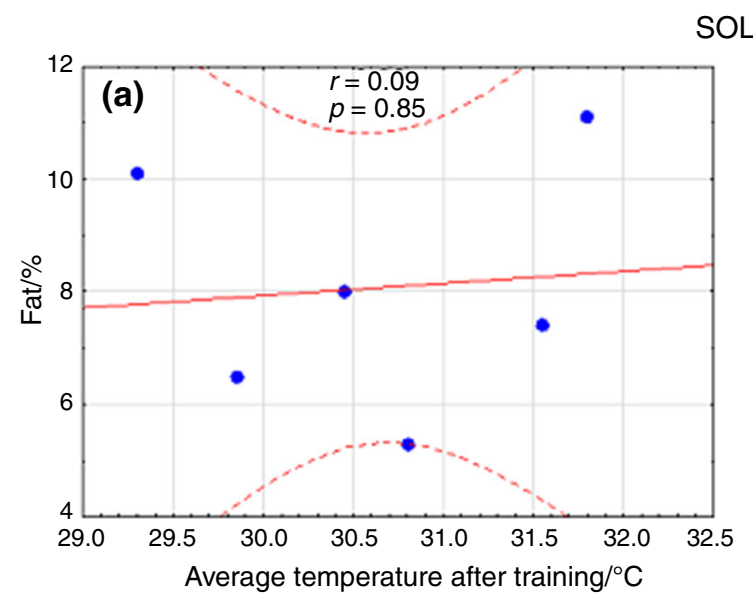

\section{OLEUS}

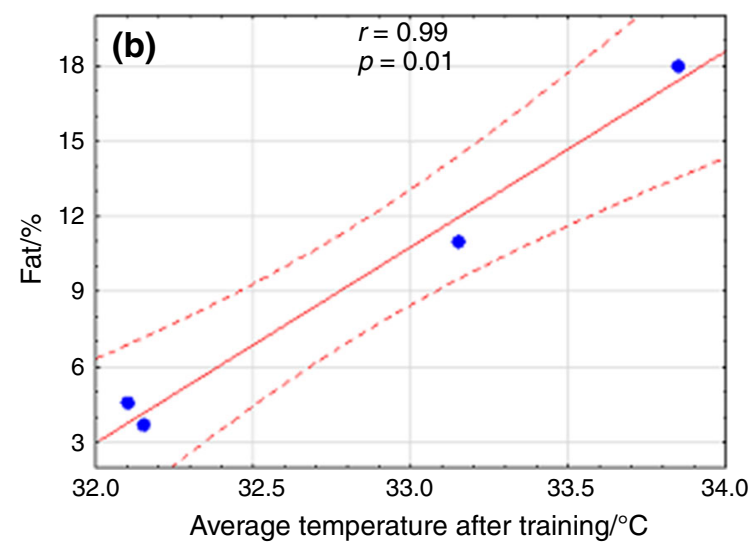

Fig. 3 Correlations of fat/\% against average temperature after training for the representative muscle of lower partof body in ski-runners (a) and swimmers (b) respectively

ability to remove excess heat from body. It was observed that CS group characterised better efficiency of the mechanisms responsible for heat removal (statistical drop of temperature of upper part of body due to evaporation unlike swimmers, see Tables 2 and 3) was more burdened during the exercise test and continued to exercise for a longer period of time, keeping heart rate close to swimmers).

\section{Conclusions}

Our pilot study showed dissimilarities in skin temperature distribution in elite athletes with different sport skills subjected to the same endurance exercise on treadmill. Moreover, significant (though not many) correlations of physiological $\left(\mathrm{WR}_{\mathrm{T}}, \mathrm{VO}_{2 \mathrm{max}}\right)$, biochemical $\left(\mathrm{LA}_{\mathrm{T}}, \mathrm{LDH}_{\mathrm{T}}\right)$ and morphological parameters (\% fat) with average temperature after exercise test were found for different muscle zones in swimmers and cross-country skiers. These findings can provide additional information on the muscle work in the different sport disciplines and may be helpful in efficiency evaluation of athletes. However, further investigation is needed for validation of results.

Acknowledgements This study was supported by statutory funds of University of Silesia, Poland and partly by Grant Ministry of Science and Higher Education (Poland)/Nr0050/RS4/2016/54.

\section{Compliance with ethical standards}

Conflict of interest The authors declare that they have no conflict of interest.

Open Access This article is distributed under the terms of the Creative Commons Attribution 4.0 International License (http://creative commons.org/licenses/by/4.0/), which permits unrestricted use, distribution, and reproduction in any medium, provided you give appropriate credit to the original author(s) and the source, provide a link to the Creative Commons license, and indicate if changes were made.

\section{References}

1. Marins JCB, Fernández-Cuevas I, Arnaiz-Lastras J, Fernandes AA, Sillero-Quintana M. Applications of infrared thermography in sports. A review. Revista Internacional de Medicina y Ciencias de la Actividad Física y el Deporte. 2015;15(60):805-24.

2. Fernández-Cuevas I, Sillero-Quintana M, Garcia-Conception MA, Ribot-Serrano J, Gomez-Carmona P. Monitoring skin thermal response to training with infrared thermography. New Stud Athl. 2014;29(1):57-71.

3. Hildebrandt C, Zeilberger K, Francis E, Ring J, Raschner C. The application of medical infrared thermography in sports medicine. In: Zaslav KR, editor. An international perspective on topics in sports medicine and sports injury. InTech; 2012. ISBN: 978-95351-0005-8. http://www.intechopen.com/books/an-internationalperspective-on-topics-in-sports-medicine-and-sportsinjury/theapplication-of-medical-infrared-thermography-in-sports-medicine.

4. Arfaoui A, Polidori G, Taiar R, Popa C. Infrared thermography in sports activity. In: Prakash RV, editor. Infrared thermography. InTech; 2012. ISBN: 978-953-51-0242-7. http://www.intecho pen.com/books/infrared-thermography/infrared-thermography-insports-activity.

5. Brancaccio P, Maffulli N, Limongelii FM. Creatine kinase monitoring in sport medicine. Br Med Bull. 2007;81-82:209-30.

6. Banfi G, Lombardi G, Lubkowska A. Metabolic markers in sports medicine. Adv Clin Chem. 2012;56:1-54.

7. Stanula A, Gabrys T, Szmatlan-Gabrys U, Roczniok R, Maszczyk A, Pietraszewski P. Calculating lactate anaerobic thresholds in sports involving different endurance preparation. J Exerc Sci Fit. 2013;11:12-8.

8. Sprynarova S, Bass A, Mackova E, Vondra K, Vitek V, Teisinger $\mathrm{J}$, Malkovska M. Changes in maximal aerobić power, aerobic capacity, and muscle enzyme activities at two stages of the annual training cycle in ski-runners. Eur J Appl Physiol. 1980;44:17-23.

9. Mackova E, Melichna J, Vondra K, Jurimae T, Paul T, Novak J. The relationship between anaerobic performance and muscle metabolic capacity and fibre distribution. Eur J Appl Physiol. 1985;54:413-5. 
10. Lindinger SJ, Holmberg H-C, Muller E, Rapp W. Changes in upper body muscle activity with increasing double poling velocities in elite cross-country skiing. Eur J Appl Physiol. 2009;106:353-63.

11. Akimov EB, Son'kin VD. Skin temperature and lactate threshold during muscle work in athlets. Hum Physiol. 2011;37(5):621-8.

12. Adamczyk JG, Boguszewski D, Siewierski M. Thermographic evaluation of lactate level in capillary blood during post-exercise recovery. Kinesiology. 2014;46(2):186-92.

13. Rusko H, Rahkila P, Karvinen E. Anaerobic threshold, skeleton muscle enzymes and fiber composition in young female crosscountry skiers. Acta Phys Scand. 1980;108:263-8.

14. Losnegard T, Mikkelsen K, Rřnnestad BR, Halle J, Rud B, Raastad T. The effect of heavy strength training on muscle mass and physical performance in elite cross country skiers. Scand J Med Sci Sports. 2011;2:389-401.

15. Stöggl T, Müller E, Ainegren M, Holmberg H-C. General strength and kinetics: fundamental to sprinting faster in cross country skiing? Scand J Med Sci Sports. 2011;21:791-803.

16. Holmberg H-C, Lindinger S, Stöggl T, Eitzlmair E, Müller E. Biomechanical analysis of fubel poling in elite cross-country skiers. Med Sci Sports Exerc. 2005;37(5):807-18. https://doi.org/ 10.1249/01.MSS.0000162615.47763.C8.

17. Zaïdi H, Taïar R, Fohanno S, Polidori G. The influence of swimming type on the skin-temperature maps of a competitive swimmer from infrared thermography. Acta Bioeng Biomech. 2007;9(1):47-51.

18. Ramadan W, Rybarova S, Zacha D, Novotny J Jr, Bernacikova M, Novotny J. Thermographic evaluation of muscle activity after front crawl swimming in young men. Acta Bioeng Biomech. 2017. https://doi.org/10.5277/ABB-00924-2017-03.

19. Novotny J, Rybarova S, Zacha D, Novotny J Jr, Bernacikova M, Ramadan W. The influence of breaststroke swimming on the muscle activity of young men in thermographic imaging. Acta Bioeng Biomech. 2015;17(2):121-9.

20. Rybarova S, Novotny J. Skin temperature changes of muscle regions in training swimmers. $J$ Hum Sport Exerc. 2015;10(1):S192-7.

21. Ammer K. The Glamorgan Protocol for recording and evaluation of thermal images of the human body. Thermol Int. 2008;18(4):125-44.

22. Ring EFJ, Ammer L. The technique of infrared imaging in medicine. Thermol Int. 2000;10(1):7-14.

23. Tanda G. Total body skin temperature of runners during treadmill exercise. A pilot study. J Therm Anal Calorim. 2018;131:1967-77.

24. Tanda G. Skin temperature measurements by infrared thermography during running exercise. Exp Therm Fluid Sci. 2016;71:103-13.

25. Merla A, Mattei PA, Di Donato L, Romani GL. Thermal imaging of cutaneous temperature modifications in runners during graded exercise. Ann Biomed Eng. 2010;38:158-63.

26. Ludwig N, Trecroci A, Gargano M, Formenti D, Bosio A, Rampinini E, Alberti G. Thermography for skin temperature evaluation during dynamic exercise, a case study on an incremental maximal test in elite male cyclist. Appl Opt. 2016;55(34):1-5. https://doi.org/10.1364/AO.99.099999.

27. Pokora I, Żebrowska A. Application of A Physiological Strain Index in evaluating responses to exercise stress-a comparison between endurance and high intensity intermittent trained athletes. J Hum Kinet. 2016;50(1):103-14.

28. Roels B, Schmitt L, Libicz S, Bentley D, Richalet J, Millet G. Specificity of $\mathrm{VO}_{2 \max }$ and the ventilatory threshold in free swimming and cycle ergometry: comparison between triathletes and swimmers. Br J Sports Med. 2005;39(12):965-96.

29. Pokora I. Relationships between electromiographic characteristics, mechanical work efficiency and body temperatures during running exercise test in men. J Hum Kinet. 2004;11:3-5.

30. Drzazga Z, Cholewka A, Ciszek W, Czuba MC, Poprzęcki S. Body temperature depression to training exercise in normobaric hypoxia-primary studies. In: IFMBE proceedings, vol. 45; 2015, p. 232-235.

31. Choi JK, Miki K, Sagawa S, Shiraki K. Evaluation of mean skin temperature formulas by infrared thermography. Int J Biometeorol. 1997;41:68-75.

32. Cholewka A, Kasprzyk T, Stanek A, Sieroń-Stołtny K, Drzazga Z. May thermal imaging be useful in cyclist endurance tests? J Therm Anal Calorim. 2016;123:1973-9. https://doi.org/10. 1007/s10973-015-4662-5.

33. Fernandes AA, Amorim PRS, Brito CJ, Siller-Quitana M, Marins JCB. Regional skin temperature response to moderate aerobic exercise measured by infrared thermography. Asian J Sports Med. 2016;7(1):e29243.

34. Thelen DG, Chumanov ES, Hoerth DM, Best TM, Swanson SC, Li L, Young M, Heiderscheit BC. Hamstring muscle kinematics during treadmill sprinting. Med Sci Sports Exerc. 2005;37:108-14.

35. Hof AL, Nauta J, van der Knaap ER, Schallig MA, Struwe DP. Calf muscles work and segment energy changes in human treadmill walking. J Electromyogr Kinesiol. 1992;2(4):203-16. https://doi.org/10.1016/1050-6411(92)90024-D.

36. Chudecka M, Lubkowska A. The use of thermal imaging to evaluate body temperature changes of athletes during training and a study on the impact of physiological and morphological factors on skin temperature. Hum Mov. 2012;13(1):33-9.

37. Adamczyk JG, Olszewska M, Boguszewski D, Białoszewski D, Reaburn P. Is it possible to create a thermal model of warm-up? Monitoring of the training process in athletic decathlon. Infrared Phys Technol. 2016;76:555-9.

38. Boguszewski D, Adamczyk JG, Urbańska N, Mrozek N, Piejko $\mathrm{K}$, Janicka M, Białoszewski D. Using thermal imaging to assess the effect of classical massage on selected physiological parameters of upper limbs. Biomed Hum Kinet. 2014;6:146-50.

39. Formenti D, Ludwig N, Gargano M, Gondola M, Dellerma N, Caumo A, Alberti G. Thermal imaging of exercise-associated skin temperature changes in trained and untrained female subjects. Ann Biomed Eng. 2013;41:863-71.

40. Ammer K. Can the source of metabolic heat be seen by infrared thermal imaging? Presented on XXI Meeting of the Polish Society of Medical Thermography Combined with The European Association of Thermology, Zakopane; 2017.

41. Chudecka M, Lubkowska A, Kempińska-Podohordecka A. Body surface temperature distribution in relation to body composition in obese women. J Therm Biol. 2014;43:1-6.

42. Schlader ZJ, Stannard SR, Mundel T. Human thermoregulatory behaviour during rest and exercise-a prospective review. Physiol Behav. 2010;99(3):269-75. 